\title{
Understanding factors that contribute to the disposal of unused opioid medication
}

\author{
Daniel E Buffington ${ }^{1,2}$ \\ Alyson Lozicki \\ Thomas Alfieri ${ }^{3}$ \\ T Christopher Bond ${ }^{3}$ \\ 'University of South Florida, College \\ of Medicine, ${ }^{2}$ University of South \\ Florida, College of Pharmacy, Tampa, \\ FL 33617, USA; ${ }^{3}$ Purdue Pharma LP, \\ Medical Affairs, Stamford, CT 0690I, \\ USA
}

This article was published in the following Dove Medical Press journal: Journal of Pain Research

Purpose: Drivers of excess controlled substance disposal behaviors are not well understood. A survey of patients who had received opioid-based medications was conducted to inform the design of future innovative drug take-back programs.

Methods: This was a cross-sectional survey study conducted in 152 participants who received treatment with an opioid within the previous 2 years and had possession of unused medication following either switching to a different opioid or discontinuation of pain.

Results: Approximately one-third of patients had disposed of their unused opioid medication. Education about the importance of and appropriate methods for drug disposal was associated with a significantly increased likelihood of patients disposing of unused medication, and it was observed that patients prescribed an immediate-release/short-acting opioid were twice as likely to keep their medication compared to those prescribed an extended-release/long-acting opioid. The most commonly reported methods for disposal were via drug return kiosks and flushing the medication down the toilet. Some of the most impactful drivers of unused opioid disposal were routine practice of disposing of all unused drugs and instruction from a health care provider, and the most common driver of keeping unused medication was the desire to have it on-hand should there be a need to treat pain in the future. Over $80 \%$ of patients indicated that they would be more likely to use a drug take-back service if they were offered compensation or if the kiosk was in a location that they visited frequently, and approximately half of the patients indicated that they would be willing to request an initial partial fill of an opioid prescription to reduce the volume of unused medication.

Conclusion: There is a clear need to increase patient awareness about the importance and methods of proper medication disposal, and a great opportunity for health care providers to increase patient education efforts. These study findings also highlight key areas for improvement in drug take-back programs that may promote and incentivize more patients to utilize the services. Keywords: pain management, patient education, drug diversion, medication safety, drug take back

\section{Introduction}

Despite the national- and state-level implementation of many regulatory processes focused on reducing drug trafficking, inappropriate prescribing practices, and indiscriminate dispensing, the constant rise in the number of opioid-related deaths highlights a need to look into other factors contributing to this epidemic. Drug diversion occurring at the patient level subsequent to appropriate prescribing and dispensing is of significant concern. The 2016 National Survey on Drug Use and Health indicates that in the US $\sim 3.3$ million people 12 years or older are current misusers of prescription
Correspondence: Thomas Alfieri Purdue Pharma LP, 20I Tresser Blvd, Stamford, CT 0690I, USA

Tel + I 4752996085

Email Thomas.Alfieri@pharma.com 
pain relievers, with $\sim 53 \%$ of these individuals obtaining the pain medication from friends or family with or without their knowledge. ${ }^{1}$

According to the National Community Pharmacists Association, up to $40 \%$ of prescription medications are not completely used and are likely to remain inside the home where the storage of these medication doses may not be secure posing a risk for unintentional poisoning events or diversion. ${ }^{2}$ Given these statistics, proper disposal of unused prescription opioid medications is imperative in minimizing the incidence of opioid misuse and reducing the risks for accidental poisoning. ${ }^{3}$

Since 2010, the Drug Enforcement Administration has supported disposal efforts and has collected more than 9 million pounds of potentially dangerous unused, unwanted, or expired prescription drugs at biannual National Prescription Drug Take-Back Days. Although a significant amount of medicine has been collected at these events, there is a lack of data that specifically captures the motivations of controlled substance disposal behaviors. ${ }^{4,5}$ A survey was conducted to better understand drivers of disposal behavior and to inform the design of future disposal and take-back programs.

\section{Methods}

A cross-sectional survey study was conducted from September 2016 to October 2016 to assess the behaviors and drivers of the disposing of unused opioid medication. An invitation to participate in the survey was disseminated via e-mail to patients belonging to an independent research group. This study met the criteria for exemption from full IRB review as it posed minimal risk of harm to patients and no identifying information was collected.

Eligibility for inclusion in this study was determined by participant responses to a brief questionnaire that was completed prior to beginning the survey. Patients were included if they had a history of acute or chronic pain, had been treated with prescription opioid medication within the preceding 2 years, and had unused (leftover) opioid medication. Demographic data and participant characteristics collected included type of pain, opioid(s) prescribed, quantity originally prescribed, and quantity remaining. Survey questions addressed history of disposing of unused opioid medication, motivations for disposing of or keeping unused medication, beliefs about incentives used to promote safe opioid disposal, and barriers to utilizing medication take-back programs. Data analysis was performed using only completed survey responses and results are presented as descriptive statistics. Categorical data are presented as counts and percentages. Subgroup analyses were performed using Fisher's exact test with an alpha of 0.05 , and relative risk was calculated.

\section{Results}

The survey response rate was $8.9 \%(n=1,111)$, and of the patients who met the inclusion criteria the survey completion rate was $85.9 \%(n=152)$ (Figure 1). Participant demographics and characteristics are summarized in Table 1 . The majority of patients included in this study were female and aged 35-64 years. The most common types of pain for which opioids were prescribed were back/neck pain and arthritis, and the most commonly prescribed opioids were hydrocodone/ acetaminophen and oxycodone/acetaminophen. Greater than $50 \%$ of patients were prescribed only an immediate-release or short-acting (IR/SA) opioid.

\section{Education about opioid medication disposal}

Forty percent $(n=60)$ of patients reported that they received information about the importance of properly disposing of unused opioid medication, and of these $50 \%(n=30)$ reported that they received the information from a pharmacist and $33.3 \%(n=20)$ reported that they received the information from a prescriber or someone affiliated with the prescriber. Similarly, $36.2 \%$ of patients reported that they received information about appropriate methods for disposing of unused medication, and of these $45.5 \%(n=25)$ received the information from a pharmacist and $45.5 \%(n=25)$ received the information from their prescriber or someone affiliated with their prescriber. This information was communicated to patients most frequently in the setting of an in-person conversation ( $47 \%$ ) or provided in the form of printed material containing all of the necessary information $(34.7 \%)$.

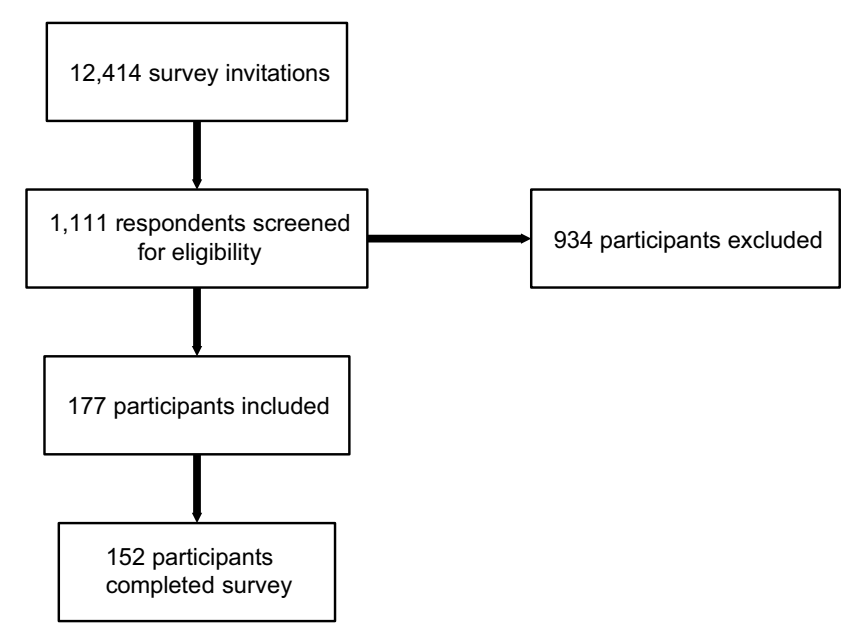

Figure I Participant flow diagram. 
Table I Demographics and characteristics of patients

\begin{tabular}{|c|c|}
\hline Characteristics & $\begin{array}{l}\text { No. of patients } \\
\text { (\%) }\end{array}$ \\
\hline \multicolumn{2}{|l|}{ Gender } \\
\hline Male & $48(31.6)$ \\
\hline Female & $102(67.1)$ \\
\hline Unspecified & $2(1.3)$ \\
\hline \multicolumn{2}{|l|}{ Age (years) } \\
\hline $18-34$ & $6(3.9)$ \\
\hline $35-64$ & $115(75.7)$ \\
\hline $65+$ & $31(20.4)$ \\
\hline \multicolumn{2}{|l|}{ Type of pain } \\
\hline Acute & $14(9.2)$ \\
\hline Chronic & $52(34.2)$ \\
\hline Both acute and chronic & $86(56.6)$ \\
\hline \multicolumn{2}{|l|}{ Type of chronic pain $(\mathrm{N}=138)$} \\
\hline Arthritis & $80(58.0)$ \\
\hline Back/neck pain & $92(66.7)$ \\
\hline Fibromyalgia & $27(19.6)$ \\
\hline Gastrointestinal & $35(25.4)$ \\
\hline Neuropathy & $32(23.2)$ \\
\hline Headache & $44(31.9)$ \\
\hline Other & $26(18.8)$ \\
\hline \multicolumn{2}{|l|}{ Prescriber } \\
\hline Primary care practitioner & $60(39.5)$ \\
\hline Pain specialist & $35(23.0)$ \\
\hline Physician assistant (PA) & I $(0.7)$ \\
\hline Dentist & $8(5.3)$ \\
\hline Other & $48(31.6)$ \\
\hline \multicolumn{2}{|l|}{ Opioid prescribed } \\
\hline Codeine & $18(11.8)$ \\
\hline Fentanyl & $6(3.9)$ \\
\hline Hydrocodone & $19(12.5)$ \\
\hline Hydrocodone/acetaminophen & $79(52.0)$ \\
\hline Hydromorphone & $8(5.3)$ \\
\hline Meperidine & $3(2.0)$ \\
\hline Methadone & $3(2.0)$ \\
\hline Morphine & II (7.2) \\
\hline Oxycodone & $27(17.8)$ \\
\hline Oxycodone/acetaminophen & 47 (30.9) \\
\hline Buprenorphine & $3(2.0)$ \\
\hline Other & $9(5.9)$ \\
\hline Unsure & $5(3.3)$ \\
\hline \multicolumn{2}{|l|}{ Opioid dosage form prescribed } \\
\hline Immediate-release or short-acting (IR/SA) & $94(6 \mid .8)$ \\
\hline Extended-release or long-acting (ER/LA) & $17(11.2)$ \\
\hline Both $I R / S A$ and ER/LA & $21(13.8)$ \\
\hline Unsure & $20(13.2)$ \\
\hline \multicolumn{2}{|l|}{ Opioid day's supply prescribed } \\
\hline$<3$ days & $4(2.6)$ \\
\hline 3-7 days & $38(25.0)$ \\
\hline $8-14$ days & $33(21.7)$ \\
\hline 15-29 days & $22(14.5)$ \\
\hline 30 days or more & $54(35.5)$ \\
\hline Unsure & $\mathrm{I}(0.7)$ \\
\hline Mean quantity prescribed (SD) & $45.7( \pm 46.4)$ \\
\hline Mean quantity unused (SD) & $13.0( \pm 13.7)$ \\
\hline
\end{tabular}

Additional forms of communication included printed material with a link to a website to obtain more information $(8.7 \%)$, a conversation over the phone (4.4\%), and electronic communication (4.3\%). Additionally, $12.5 \%(n=19)$ of patients reported that they received a reminder to dispose of unused opioid medication from a pharmacist, prescriber, or someone other than a health care provider.

\section{Unused medication disposal behavior}

Only $33 \%(n=50)$ of patients reported that they disposed of their unused opioid medication. Most patients kept the medication, and a few gave the medication to someone else or reported "other" when asked what they did with their unused opioid medication (Figure 2). The most frequently reported methods for disposal were via a drug disposal kiosk or other local take-back program $(50 \% ; n=25)$ and flushing the medication down the toilet $(26 \% ; n=13)$. Additional methods included disposing the medication in the trash $(16 \%$; $\mathrm{n}=8)$ and other unspecified methods $(8 \% ; n=4)$. Most patients $(62 \% ; n=31)$ reported disposing of their unused medication within less than 1 week to 1 month of discontinuing the opioid, $26 \%(n=13)$ of patients waited 1-3 months before disposal, $8 \%(n=4)$ waited up to 1 year before disposal, and $4 \%(n=2)$ kept the unused medication longer than 1 year before disposing it of.

The factors influencing patients' decisions to dispose of or keep unused opioid medication are summarized in Tables 2 and 3, respectively, and ranked according to weight of influence. The greatest influencing factor in the decision to

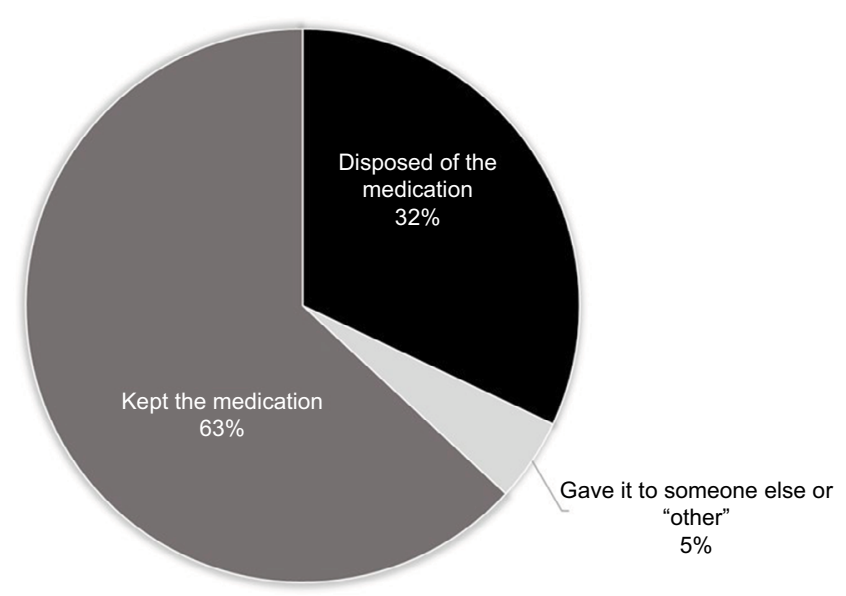

Figure 2 Participant behavior regarding unused opioid medication. 
Table 2 Motivations of unused opioid medication disposal

\begin{tabular}{|l|l|}
\hline Rank & Influencing factors \\
\hline 2 & $\begin{array}{l}\text { I dispose of all unused prescription medication as a } \\
\text { routine practice } \\
\text { I dispose of all opioids because I am particularly aware of } \\
\text { the risk they pose } \\
\text { I dispose of my medications when they reach the } \\
\text { expiration date } \\
\text { I was instructed by a health care practitioner whom I } \\
\text { trust } \\
\text { I was concerned about someone taking and using them } \\
\text { I was concerned a child could accidentally find and ingest } \\
\text { the opioids } \\
6\end{array}$ \\
$\begin{array}{l}\text { Other } \\
\text { I was concerned I would feel pressured to give my } \\
\text { unused opioids to someone } \\
\text { I was concerned I might be tempted to use the leftover } \\
\text { opioids in the future } \\
\text { I received a reminder }\end{array}$ \\
\hline
\end{tabular}

dispose of unused opioid medication was a routine practice of disposing of "all" unused medication, and the least influential factor was receipt of a reminder. For patients that kept their unused opioid medication, the greatest influencing factor was a desire to have the medication on-hand should they need it in the future, and the least influential factor was a reported addiction to opioids.

In a subgroup analysis, it was observed that patients that received information about the importance of and methods for appropriate medication disposal reported a greater frequency of unused opioid medication disposal compared to those that did not receive any information. Additionally, a significantly greater proportion of patients that were prescribed only an extended-release or long-acting opioid (ER/LA) disposed of their unused medication compared to those who were prescribed only an IR/SA form (Table 4).

Table 3 Motivations of unused opioid medication retention

\begin{tabular}{|c|c|}
\hline Rank & Influencing factor \\
\hline 1 & A desire to have effective pain therapy immediately available should you require such pain therapy in the future for the same condition \\
\hline 2 & A desire to have effective pain therapy immediately available should you require such pain therapy in the future for a different condition \\
\hline 3 & $\begin{array}{l}\text { A belief that the unused prescription opioids have a value and should not simply be thrown away even though you had no specific use in } \\
\text { mind }\end{array}$ \\
\hline 4 & $\begin{array}{l}\text { A desire to have effective pain therapy immediately available should a friend or family member ever require such pain therapy in the } \\
\text { future }\end{array}$ \\
\hline 5 & $\begin{array}{l}\text { Concern about the environmental impact of disposing of unused prescription opioids via the methods recommended to me (eg, flushing } \\
\text { the tablets or throwing them out in the trash) }\end{array}$ \\
\hline 6 & Other \\
\hline 7 & Insufficient information or awareness of the disposal methods that were available to you \\
\hline 8 & $\begin{array}{l}\text { Inconvenience of disposing of unused prescription opioids via take-back programs or disposal kiosks, and insufficient motivation or time } \\
\text { to dispose of the medication despite being aware that all unused opioids should be disposed of }\end{array}$ \\
\hline 9 & A desire to recreationally use the unused prescription opioids to achieve psychoactive effects \\
\hline 10 & The stigma associated with disposing of unused prescription opioids via take-back programs or disposal kiosks \\
\hline 11 & An addiction to prescription opioids that made you desire them even after your pain was relieved \\
\hline
\end{tabular}

Table 4 Subgroup analysis of proportion of patients who disposed of unused opioid medication

\begin{tabular}{|c|c|c|c|}
\hline Subgroups & No. of patients (\%) & $\mathbf{R R}(95 \% \mathrm{CI})$ & $P$-value \\
\hline \multicolumn{4}{|c|}{$\begin{array}{l}\text { Received information about the importance of proper opioid medication } \\
\text { disposal }(n=60)\end{array}$} \\
\hline Yes & $31(5 \mid .7)$ & \multirow[t]{3}{*}{$2.50(1.56-4.00)$} & \multirow[t]{3}{*}{$<0.0001$} \\
\hline No & $19(20.7)$ & & \\
\hline $\begin{array}{l}\text { Received information about appropriate methods for opic } \\
\text { disposal }(n=55)\end{array}$ & & & \\
\hline Yes & $31(56.4)$ & \multirow[t]{3}{*}{$2.88(1.81-4.58)$} & \multirow[t]{3}{*}{$<0.0001$} \\
\hline No & $19(19.6)$ & & \\
\hline \multicolumn{2}{|l|}{ Opioid dosage form } & & \\
\hline Immediate-release or short-acting (IR/SA) only $(n=94)$ & $24(25.5)$ & \multirow[t]{2}{*}{ a $0.43(0.26-0.73)$} & \multirow[t]{2}{*}{${ }^{\mathrm{a}} 0.01$} \\
\hline Extended-release or long-acting (ER/LA) only $(n=17)$ & $10(58.8)$ & & \\
\hline Both IR/SA and ER/LA ( $n=2 I)$ & $9(42.9)$ & $\begin{array}{l}\mathrm{b} 0.60(0.33-1.09) \\
\mathrm{cl} 1.37(0.73-2.59)\end{array}$ & $\begin{array}{l}\mathrm{b} 0.19 \\
0.51\end{array}$ \\
\hline
\end{tabular}

Notes: ${ }^{a} \mathrm{R} / \mathrm{SA}$ vs ER/LA; ${ }^{\mathrm{b} I R / S A}$ only vs both; ' ${ }^{\mathrm{E} R} / \mathrm{LA}$ only vs both. 


\section{Incentives to promote safe medication disposal}

A high percentage of patients $(82.9 \% ; n=126)$ reported that they would be more likely to use a medication disposal kiosk or mail-in program if a small incentive was offered (eg, US\$1-\$5 value). The preferred type of incentive was cash, and patients reported a desired value ranging from US\$1 to the original cost of the prescription. Additional forms of compensation that patients agreed would incentivize them to dispose of unused medication are summarized in Figure 3.

When asked about the likelihood of utilizing a drug take-back program, most patients reported that they would be "very likely" or "somewhat likely" to use a medication disposal kiosk at a location that they frequented, less than $50 \%$ indicated that they would be likely to use a kiosk at a location they did not normally visit, and over half of the patients indicated that they would be likely to use a licensed mail-in program that provided a prepaid envelope (Figure 4).

Of those patients who indicated that they were unlikely to use a medication disposal kiosk at a location they already frequented $(n=8)$, the most commonly reported barriers to using this method were that they did not plan to dispose of medications at all $(n=4)$, concerns for privacy $(n=1)$, and concerns that the opioid would "fall into the wrong hands" $(n=3)$.

Of those patients who indicated that they were unlikely to use a mail-in program $(n=24)$, the barriers to using this method were that they did not plan to dispose of medica-

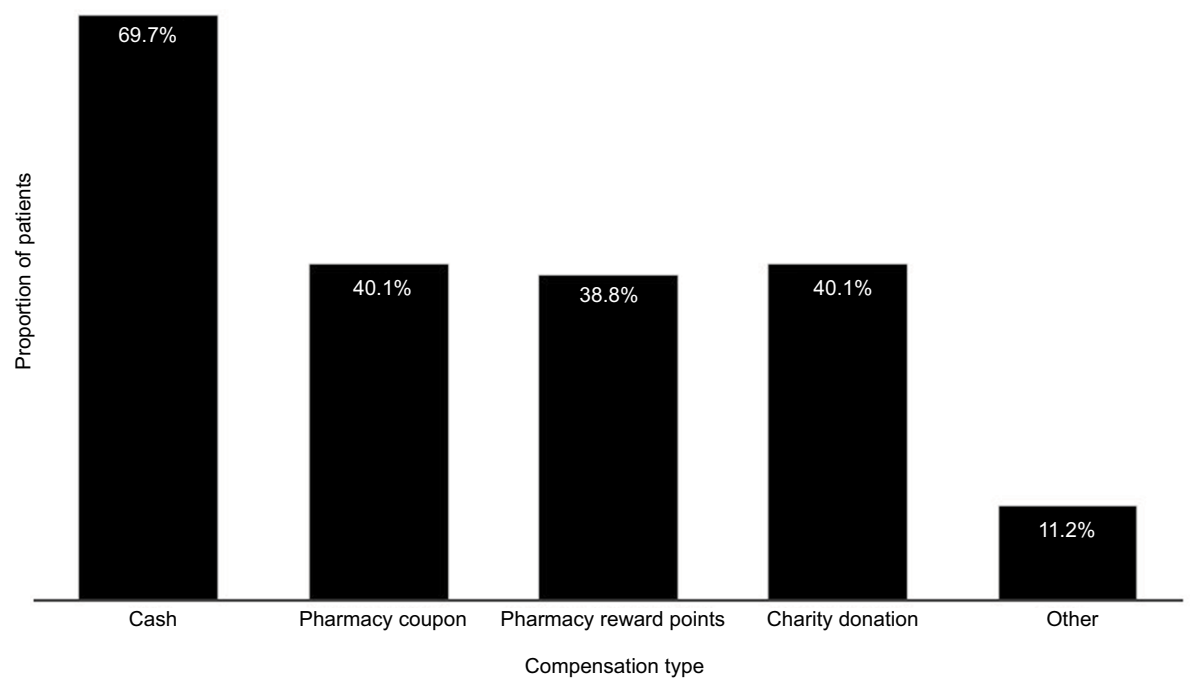

Figure 3 Proportion of patients who reported that compensation would lead them to dispose of unused opioid medication.

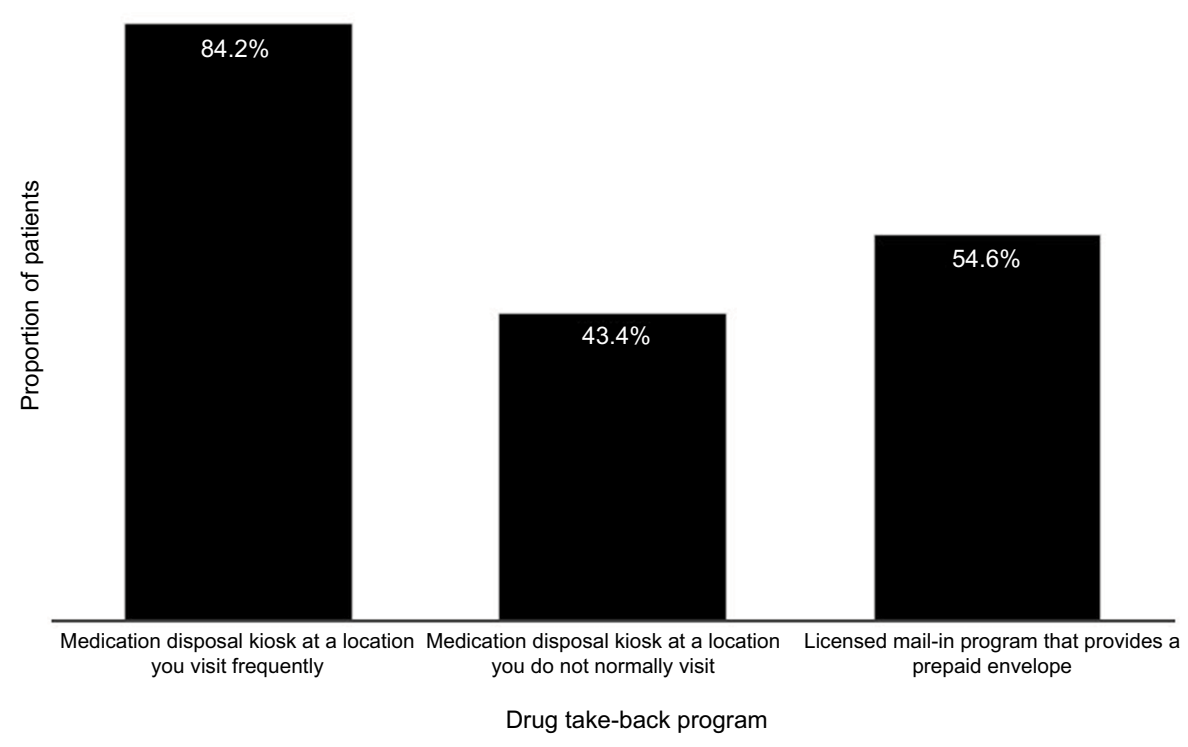

Figure 4 Proportion of patients "very likely" or "somewhat likely" to utilize a medication disposal kiosk or mail-in drug take-back program. 
tions at all $(n=6)$, concerns for privacy $(n=3)$, concerns that the opioid would "fall into the wrong hands" $(n=12)$, and convenience $(n=3)$.

When asked about the likelihood of requesting a partial fill of an opioid prescription if given the option, about $51 \%$ $(n=77)$ of the patients indicated that they would be "very likely" or "likely" to select this option (Figure 5). In those who indicated they would be unlikely to request a partial fill $(n=51)$, the most significant barrier indicated was concern that they would not have the medication if needed $(n=35)$, the inconvenience of returning to the pharmacy to fill the remaining quantity $(n=30)$, belief that the prescriber wrote a prescription for the correct number of days $(n=25)$, the desire to have leftover medication should it be needed in the future $(n=24)$, and the desire to receive the full quantity of medication prescribed given that the co-pays would be the same for either a partial fill or for the full quantity $(n=28)$.

\section{Discussion}

These study data offer insights into the motivations driving the decisions to dispose of or keep unused opioid medication. Roughly one-third of the patients in this study reported disposing of their medication, and a similar proportion indicated that they had received education on the importance of and appropriate methods for disposal. The most common forms of opioid disposal were via a drug disposal kiosk or other drug take-back program and flushing them down the toilet. A significantly greater proportion of patients who received

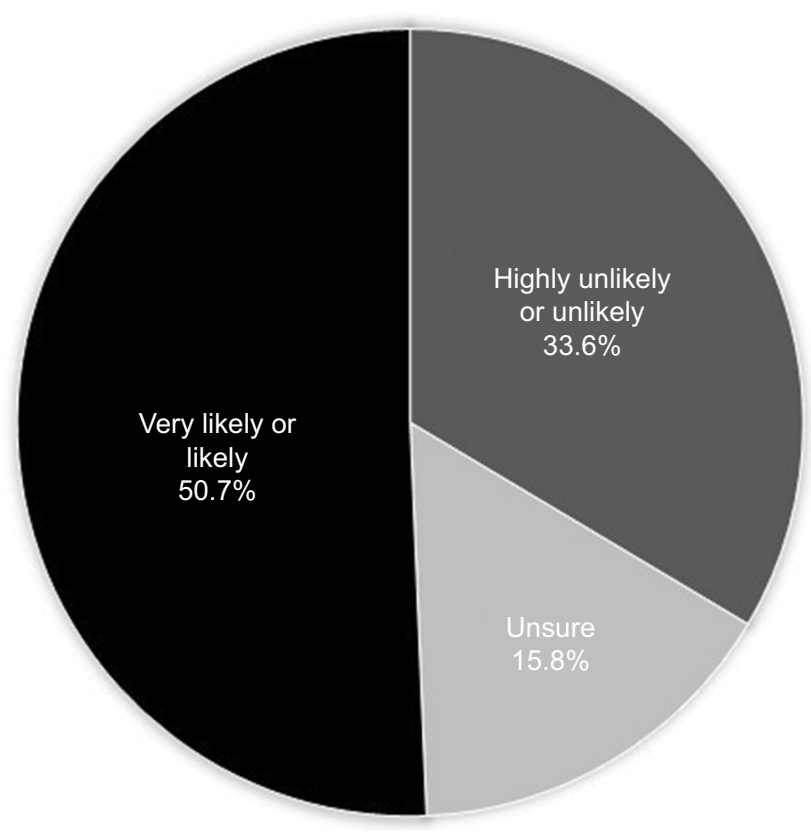

Figure $\mathbf{5}$ Likelihood of patients to request a partial fill if given the option. education about unused opioids reported disposing of them compared to those who received no information. Patients who were counseled about appropriate methods for disposal were approximately three times as likely to dispose of medication compared to those who received no counseling. Additionally, the majority of patients in this study reported having unused IR/SA opioids, and $\sim 60 \%$ indicated they had received treatment for acute pain or acute and chronic pain. A disparity in the provision of patient education when prescribing for acute vs chronic pain and/or overprescribing of opioids for acute conditions may also contribute to the increased proportion of unused IR/SA opioids compared to ER/LA.

Other observational studies support these findings and demonstrate the importance and significant impact of patient, family, and caregiver education on unused opioid disposal behaviors. $^{6-8} \mathrm{~A}$ wealth of literature exists regarding the prescribing patterns and opioid disposal education in postsurgical settings. These studies have demonstrated that most patients felt that they were prescribed too many opioids after surgery and up to $75 \%$ of these patients had unused medication after their pain dissipated, ${ }^{9,10}$ and have illustrated the staggeringly low rates of patient education on opioid disposal provided to this patient population. ${ }^{11}$ Based on this evidence, there is a clear and critical need to increase patient education and awareness with regard to proper medication disposal.

Patients in this study who disposed of unused opioids were more likely to do so as part of a routine practice of disposing of all excess medication, an awareness of the risks posed by unused opioids, or with instruction from a trusted health care provider. Very few patients received a reminder to dispose of medication; however, it was observed that reminders were ranked as one of the least influential factors in deciding to dispose of unused opioids. Those who kept their unused medication indicated that the most influential factor in their decision was a desire to have an opioid readily available should they require for future pain management therapy; the least influential factors were for recreational use or opioid addiction, and the stigma associated with disposing of unused prescription opioids via take-back programs or disposal kiosks. Additionally, a correlation between opioid dosage form and disposal was observed. Patients who were prescribed only an IR/SA were twice as likely to keep their unused medication compared to those who were prescribed only an ER/LA opioid. As the majority of patients in this study reported suffering from both acute and chronic pain, these data may be reflective of a desire for patients with difficult to manage or unpredictable pain syndromes to have medication on-hand for acute self-management of symptoms. 
This study also collected crucial data which address the utility of medication disposal kiosks and mail-in drug takeback programs, as well as common barriers to use of these methods. Over $80 \%$ of patients indicated that they would be more likely to use one of these disposal methods if a small incentive was offered, and the preferred incentive was monetary compensation at an amount ranging from US\$1 to the cost of the original prescription. Additional accepted forms of compensation included coupons, pharmacy rewards points, and even charitable donations. As the purpose of this study was to determine what motivates patients to engage in safe medication disposal practices, this hypothetical scenario was included as a survey question. On a national or global scale, it may not be economically feasible to provide compensation (cash or other benefit) for the return of unused opioids. However, these data may serve as support for the development of smaller-scale pilot programs at point-of-care entities (eg, pharmacy or health care system) to evaluate the utility of patient compensation as a motivator.

It was also noted that nearly $85 \%$ of patients would be likely to use a drug disposal kiosk if it was placed in a location that they visited frequently. Addressing both of these concerns may be an effective means of incentivizing patients to utilize these programs. National drug take-back events have been successful in recovering a large volume of unused noncontrolled substances as they are a highly advertised, convenient way for patients to return unused medication. However, controlled substances account for less than $10 \%$ of the total quantity of medications collected, and it remains unclear what proportion of all unused opioids are represented by these data. ${ }^{12,13}$ Other drug disposal programs such as kiosks or mail-in services have much less available data. Further research should evaluate the implementation of compensation (monetary or other benefits) and/or the increased advertising of conveniently located programs for the safe disposal of unused opioid medication.

Finally, this study assessed the likelihood of patients to request a partial fill of opioids as a way to reduce the quantity of unused medication they are left with. Patients were presented with a hypothetical scenario in which they could opt to initially fill a 7-day supply (original prescription for 30-day supply) and request to fill the remainder of the prescription if additional medication was needed. About 50\% of patients indicated that they would be likely to request a partial fill initially if given the option. Since this survey was conducted, the US Controlled Substances Act was amended to allow the partial filling of schedule II controlled substances
(CII), if requested by the patient or provider, and not prohibited by state law. ${ }^{14}$ Several states have since followed suit and amended legislation to allow patients and prescribers to request a partial fill of CII prescriptions. Efforts should be made to increase patient and prescriber awareness of this option in eligible states. Additional research and trend analysis would provide valuable metrics for the evaluation of effective patient motivation factors surrounding opioid waste reduction, ultimately reducing the risk of prescription drug abuse and diversion.

This survey included a convenience sample of 152 patients from an established patient repository. Patients selfselected to participate in the survey research group panel, and the response rate in this study was low, which introduces the potential for nonresponse bias. Additionally, selection bias is inherent in this study due to the use of a research panel, and the limited demographic data collected could further increase the potential for bias. It cannot be assumed that the respondents are representative of all patients who have unused opioid medication. Finally, the validity of these data relies on the accuracy of self-report, and the nature of the survey questions may have produced a social desirability bias where patients who did not dispose of their medication may have felt pressure to indicate that they did so (making the observed $33 \%$ disposal rate too high).

\section{Conclusion}

These results demonstrate the importance and positive impact of patient education on medication disposal behaviors and highlight the need to address patients' concerns regarding what to do with unused opioid medication and the barriers to accessing drug disposal kiosks or take-back programs. The most common motivation for keeping unused opioids, and the primary concern with requesting a partial fill, was the desire to have it on-hand should it be needed for pain relief in the future. These study data reveal the need for health care providers to educate every patient on the importance of and the appropriate methods for the disposal of unused opioid medications, and to engage the patient in the development of an individualized pain management care plan to ensure safe and effective treatment outcomes.

\section{Acknowledgments}

Medical writing support was provided by Melanie Jardim, Evidera, and Richa Attre, PhD, an employee of Purdue Pharma LP at the time of this work. This research was funded by Purdue Pharma LP. 


\section{Disclosure}

TA is an employee of Purdue Pharma LP. TCB was employed by Purdue Pharma LP at the time this study was conducted. $\mathrm{DEB}$ and $\mathrm{AL}$ received no compensation for participation in the research study, data analysis, or writing of the manuscript. The authors report no other conflicts of interest in this work.

\section{References}

1. Substance Abuse and Mental Health Services Administration. Key substance use and mental health indicators in the United States: Results from the 2016 National Survey on Drug Use and Health (HHS Publication No. SMA 17-5044, NSDUH Series H-52). Rockville, MD: Center for Behavioral Health Statistics and Quality, Substance Abuse and Mental Health Services Administration; 2017. Available from: https://store. samhsa.gov/system/files/sma17-5044.pdf. Accessed January 23, 2019.

2. Lewis ET, Cucciare MA, Trafton JA. What do patients do with unused opioid medications? Clin J Pain. 2014;30(8):654-662.

3. Egan KL, Gregory E, Sparks M, Wolfson M. From dispensed to disposed: evaluating the effectiveness of disposal programs through a comparison with prescription drug monitoring program data. $\mathrm{Am} \mathrm{J}$ Drug Alcohol Abuse. 2017;43(1):69-77.

4. United States Drug Enforcement Administration. Drug Enforcement Administration collects record number of unused pills as part of its 14th prescription drug take back day; November 7, 2017. Available from: https://www.dea.gov/divisions/hq/2017/hq110717.shtml. Accessed April 17, 2018.

5. The United States Department of Justice. DEA heads first-ever nationwide prescription drug Take-Back day. Available from: https://www. justice.gov/opa/pr/dea-heads-first-ever-nationwide-prescription-drugtake-back-day. Accessed April 17, 2018.
6. Kumar K, Gulotta LV, Dines JS, et al. Unused opioid pills after outpatient shoulder surgeries given current perioperative prescribing habits. Am J Sports Med. 2017;45(3):636-641.

7. De La Cruz M, Reddy A, Balankari V, et al. The impact of an educational program on patient practices for safe use, storage, and disposal of opioids at a comprehensive cancer center. Oncologist. 2017;22(1): 115-121.

8. Kennedy-Hendricks A, Gielen A, Mcdonald E, Mcginty EE, Shields W, Barry CL. Medication sharing, storage, and disposal practices for opioid medications among US adults. JAMA Intern Med. 2016;176(7): 1027-1029.

9. Thiels CA, Ubl DS, Yost KJ, et al. Results of a prospective, multicenter initiative aimed at developing opioid-prescribing guidelines after surgery. Ann Surg. 2018;268(3):457-468.

10. Bicket MC, Long JJ, Pronovost PJ, Alexander GC, Wu CL, Cl W. Prescription opioid analgesics commonly unused after surgery: a systematic review. JAMA Surg. 2017;152(11):1066-1071.

11. Fujii MH, Hodges AC, Russell RL, et al. Post-discharge opioid prescribing and use after common surgical procedure. J Am Coll Surg. 2018;226(6):1004-1012.

12. Stewart H, Malinowski A, Ochs L, Jaramillo J, Mccall K, Sullivan M. Inside Maine's medicine cabinet: findings from the Drug Enforcement Administration medication Take-Back events. Am J Public Health. 2015;105(1):e65-e71.

13. Ma CS, Batz F, Juarez DT, Ladao LC. Drug take back in Hawai'i: partnership between the University of Hawai'i Hilo College of pharmacy and the narcotics enforcement division. Hawaii J Med Public Health. 2014;73(1):26-31.

14. Yeh BT. Legal Authorities Under the Controlled Substances Act to Combat the Opioid Crisis. Congressional Research Service. Published April 16, 2018. Available from: https://fas.org/sgp/crs/misc/R45164. pdf. Accessed October 3, 2018.
Journal of Pain Research

\section{Publish your work in this journal}

The Journal of Pain Research is an international, peer reviewed, open access, online journal that welcomes laboratory and clinical findings in the fields of pain research and the prevention and management of pain. Original research, reviews, symposium reports, hypothesis formation and commentaries are all considered for publication.

\section{Dovepress}

The manuscript management system is completely online and includes a very quick and fair peer-review system, which is all easy to use. Visit http://www.dovepress.com/testimonials.php to read real quotes from published authors. 